\title{
Zirconium-Palladium Interactions during Dry Reforming of Methane
}

N. Köpfle ${ }^{\mathrm{a}}$, L. Mayr ${ }^{\mathrm{a}, \mathrm{d}}$, P. Lackner ${ }^{\mathrm{b}}$, M. Schmid ${ }^{\mathrm{b}}$, D. Schmidmair ${ }^{\mathrm{c}}$, T. Götsch ${ }^{\mathrm{a}}$, S. Penner ${ }^{\mathrm{a}}$ and B. Klötzer ${ }^{\mathrm{a}}$

${ }^{a}$ Institute of Physical Chemistry, Leopold Franzens University Innsbruck, 6020 Innsbruck, Austria

${ }^{\mathrm{b}}$ Institute of Applied Physics, TU Wien, 1040 Vienna, Austria

${ }^{c}$ Institute of Mineralogy and Petrography, Leopold Franzens University Innsbruck, 6020 Innsbruck, Austria

${ }^{d}$ Birck Nanotechnology Center, Purdue University, IN 47907 West Lafayette, USA

Catalytic investigations on chemical-vapor-deposition (CVD)prepared $\mathrm{Pd} / \mathrm{Zr}^{0} / \mathrm{ZrO}_{\mathrm{x}} \mathrm{H}_{\mathrm{y}}$ inverse model catalysts and $\mathrm{Pd} / \mathrm{Zr}$ intermetallic compound system in dry reforming of methane (DRM) are presented. DRM, which produces syngas, is an economically favourable way to operate an SOFC by reusing the already heated $\mathrm{CO}_{2}$ exhaust. The catalytic investigations of the $\mathrm{Pd} / \mathrm{Zr}$ system yield important information for the design of novel electrode materials or external reforming catalysts. From a catalytic perspective, the initially bimetallic Pd-Zr pre-catalyst shows a distinct activity for dry reforming of methane. This activity can be ascribed to synergistic bifunctional cooperation of palladium and zirconium. Moreover, the investigations clearly demonstrate that metallic $\mathrm{Zr}$ is crucial to observe any activity. Therefore, different bulk and surface sensitive methods are used to follow the evolution of structural and redox changes of Zr. Studies of single-crystalline Pd(111) show that $\mathrm{Zr}^{0}$ is located exclusively in subsurface layers after annealing in vacuum and prior to reaction.

\section{Introduction}

Global warming, partially effected by greenhouse gas emission, is a major concern worldwide and a lot of effort is put into more sustainable energy systems. Solid Oxide Fuel Cells (SOFC) offer an efficient way to convert energy also for mobile applications. An approach for increased efficiency, i.e., reduction of the $\mathrm{CO}_{2}$ emissions per energy output is the reuse of the $\mathrm{CO}_{2}$ exhaust of an SOFC via dry reforming of methane (1). CO present in the fuel gas is not harmful to SOFCs and can also act as a fuel (2). This concepts leads to an enhanced efficiency of the fuel cell (1). In this paper the catalytic behavior of $\mathrm{Pd} / \mathrm{Zr}$ intermetallic catalysts for methane dry reforming were investigated. The chemical and physical properties of zirconia make it's yttria doped form (YSZ) to the standard electrolyte for solid oxide fuel cells. As zirconia is used as a catalyst material, also the design of novel SOFC anode electrodes for internal reforming seems possible. Beside the eventual use in SOFCs, dry reforming of methane (DRM) is an important reaction for the conversion of two climate-relevant greenhouse gases, $\mathrm{CO}_{2}$ and $\mathrm{CH}_{4}$, to useful syngas. Normally, this reaction is performed at temperatures above $\sim 970 \mathrm{~K}$. 


\section{Experimental (Methods and Techniques)}

Depending on the experiment requirements, the research was mainly performed using two experimental set-ups: a combined ultra-high vacuum (UHV)/high-pressure catalysis setup for depth-resolved near-surface spectroscopic characterization and catalytic testing of model catalysts, as well as a second UHV system that was mainly used for surface spectroscopy and STM measurements.

\section{$\underline{\text { UHV/High-Pressure Catalysis Setup at Innsbruck University }}$}

The major aspect of this setup is the direct connection of an UHV with a batch reactor. The UHV chamber is used for model catalysts preparation and surface characterization via X-ray photoelectron spectroscopy (XPS), low-energy ion scattering (LEIS) and Auger electron spectroscopy (AES). The ambient-pressure batch reactor enables catalytic studies from room temperature up to $1300 \mathrm{~K}$. The UHV chamber has a base pressure of $1 \times 10^{-9}$ mbar. For the CVD-prepared $\mathrm{Pd} / \mathrm{Zr}^{0} / \mathrm{ZrO}_{\mathrm{x}} \mathrm{H}_{\mathrm{y}}$ model catalysts were prepared on ultra-clean polycrystalline Pd foils $(20 \times 18 \mathrm{~mm})$ with a thickness of $0.125 \mathrm{~mm}$ (Goodfellow, purity: 99.95\%). Reference experiments were also done with ultra clean polycrystalline Pd foils, as well as with pure $\mathrm{ZrO}_{2}$. The zirconia reference was prepared by pre-oxidizing a 0.127 $\mathrm{mm} \mathrm{Zr}$ foil ( 1 bar $\mathrm{O}_{2}$ at $673 \mathrm{~K}$ ) with the same size (Alfa Aesar, purity: 99.95\%). All foils were cleaned in a water/ethanol ultrasonic bath for $20 \mathrm{~min}$ before inserting into UHV. Cleaning under UHV was performed by several sputter/annealing cycles (10 minutes, 873 $\mathrm{K})$ until no contaminations were observable in XPS anymore.

For catalytic testing an ambient-pressure re-circulating batch reaction cell (all quartzglass) is connected to a gas chromatograph providing either intermediate or continuous EID-MS detection to determine the exact gas composition at any point of the reaction. Continuous partial pressure detection is performed via a capillary leak to the GC-MS. The reactor with a total volume of $296 \mathrm{ml}$ is designed to measure small reaction rates and selectivity patterns from room temperature up to $1300 \mathrm{~K}$. Adding a partial pressure of 30 mbar argon to all gas mixtures allows to account for the thermal expansion due to the temperature increase and the simultaneous gas loss through the capillary leak for continuous EID-MS detection. For partial pressure calculations, all base-line-corrected MS signals are calibrated using pure substances with quantitative consideration of fragmentation. In all experiments, $\mathrm{He}$ is added to a total pressure of 1 bar. After an equilibration and premixing period of $10 \mathrm{~min}$, a heating routine (rate $26 \mathrm{~K} \mathrm{~min}^{-1}$ ) up to $1073 \mathrm{~K}$ is performed, followed by an isothermal period at $1073 \mathrm{~K}$. Detailed information of this setup can be found elsewhere (3).

\section{$\underline{\text { Surface Science UHV System at TU Wien }}$}

This UHV system consist of a preparation chamber, with a base pressure below $10^{-10}$ mbar and an analysis chamber for scanning tunneling microscopy (STM), XPS, low-energy electron diffraction (LEED) and LEIS measurements, with a base pressure of approximately $7 \times 10^{-11}$ mbar. For all measurements with this setup a Pd(111) single crystal (MaTecK) was used and prepared by cycles of 10 min sputtering $\left(2 \mathrm{keV} \mathrm{Ar}^{+}\right.$ions and a sputter-current density of approx. $2 \mu \mathrm{A} / \mathrm{cm}^{2}$ ) and $10 \mathrm{~min}$ annealing $(\mathrm{T} \approx 873 \mathrm{~K}$ ). To generate the XP spectra, a non-monochromatized $\mathrm{Mg} \mathrm{K \alpha}$ source $(\mathrm{h} v=1253.6 \mathrm{eV}, 225 \mathrm{~W})$ and a SPECS PHOIBOS 100 analyzer with a pass energy of $16 \mathrm{eV}$ were utilized. The 
photoelectrons were collected at an angle of $15^{\circ}$ with respect to the surface normal. Temperatures were measured with a K-type thermocouple spot-welded near the sample plate. STM measurements were conducted using an Omicron $\mu$-STM with electrochemically etched W tips in constant current mode. STM images were corrected for creep of the piezo scanner (4). Sample heating was performed in the preparation chamber.

$\underline{\text { Sample Preparation - CVD Prepared Inverse Model Catalysts }}$

Zirconium (IV) tert-butoxide ( $\mathrm{Zr}\left(\mathrm{O}-\mathrm{t}-\mathrm{C}_{4} \mathrm{H}_{9}\right)_{4}$, ZTB, Sigma Aldrich, purity: $\left.99.999 \%\right)$ was chosen as the CVD precursor molecule and therefore filled into a steel cylinder connected to a leak valve under Ar atmosphere. For purification, several freeze-pump-thaw cycles were performed (cooling temperature: $77 \mathrm{~K}$, freezing point ZTB: $269 \mathrm{~K}$ ). The vapor pressure of ZTB at room temperature is sufficiently high $(\sim 8 \mathrm{mbar}(5))$ for direct dosing via a leak valve into the UHV chamber. The exposure pressure was in the range of $5 \times 10^{-}$ 8 to $5 \times 10^{-6} \mathrm{mbar}$; to calculate the exposures uncorrected ion gauge measurements in Langmuir, $\left(1 \mathrm{~L}=1 \times 10^{-6}\right.$ Torr $\left.\mathrm{s}\right)$ were used. The adsorbate coverage was calculated using XPS data; the details can be found in in Refs. (6-9).

\section{$\underline{\text { Sample Preparation - Intermetallic co-melted Pd-Zr Catalysts }}$}

The preparation of the intermetallic samples was realized by heating a stack of alternating small pieces of pure, clean $\mathrm{Pd}$ and $\mathrm{Zr}$ under high vacuum conditions $\left(1 \times 10^{-7}\right.$ mbar). Resistive heating of $\mathrm{Pd}$ and $\mathrm{Zr}$ (nominal ratio $=2: 1$ ) was performed in a Ta crucible. When the sample was heated slightly above the melting point of $\mathrm{Pd}(1828 \mathrm{~K})$ a spontaneous reaction between $\mathrm{Pd}$ and $\mathrm{Zr}$ could be observed, leading to an intermetallic Pd-Zr melt. The heating was turned off immediately and the melt recrystallized to form Pd-Zr bulk phases. The corresponding XRD pattern of the initial Pd-Zr sample is made up of a complex superposition of at least two different Pd-Zr intermetallic phases (details can be found in the Results and Discussion section).

\section{Analysis of the XPS Data}

The XPS data of both setups were analyzed using the CasaXPS software program (10). For quantification and peak fitting a Shirley background was applied to all spectra and the associated Scofield relative sensitivity factors were considered for quantification. Peak fitting of the $\mathrm{Zr} 3 \mathrm{~d}$ peaks was done using a weighted sum of Gaussian and Lorenzian peak shapes and an asymmetric shape for metallic $\mathrm{Zr}$ (CasaXPS line shapes SGL(30), $\mathrm{GL}(90) \mathrm{T}(1.2)$ ). A doublet separation ( $\mathrm{Zr} \mathrm{3} \mathrm{d}_{5 / 2} \mathrm{vs}$. $\left.\mathrm{Zr} 3 \mathrm{~d}_{3 / 2}\right)$ of $2.4 \mathrm{eV}$ for both metallic $\mathrm{Zr}$ $(11,12)$ and zirconia $(12)$ was used for fitting. The doublet area ratio was kept constant at $3: 2$ as arising from spin-orbit d-electron coupling. Electron attenuation lengths were taken from the NIST database SR 82 (13). The orbital asymmetric parameter were taken from the ELETTRA online database of ref. (14). For quantification of the XPS data different models were used namely atomic percentages or a coverage/thickness model. The atomic percentage was estimated assuming homogeneously mixed elements. Since an adlayer on the substrate surface is not a homogeneous system, the coverage/thickness model should give a better representation. The $\mathrm{ZrO}_{\mathrm{x}} \mathrm{H}_{\mathrm{y}}$ surface coverage was calculated assuming a nonattenuating adlayer on a semi-infinite substrate (6-9). As the maximum $\mathrm{ZrO}_{\mathrm{x}} \mathrm{H}_{\mathrm{y}}$ layer thicknesses remained in the sub-monolayer regime in this study, the influence of a potential attenuation effect of the photoelectrons by the overlayer remained negligible even for the 


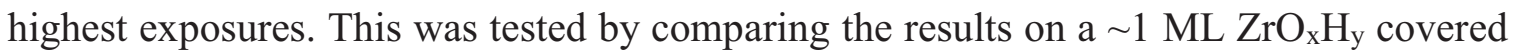
sample, using both an attenuating and non-attenuating overlayer model, which eventually showed insignificant differences. Details of these calculations are given in Refs. (6-9).

\section{$\underline{\text { Structural characterization (via XRD) }}$}

X-ray powder diffraction data were collected at ambient conditions with a Bruker AXS D8 Discover high-resolution powder diffractometer using monochromatic $\mathrm{Cu}-\mathrm{K} \alpha 1$ radiation $(\lambda=1.5406 \AA ; 40 \mathrm{kV}, 40 \mathrm{~mA})$ and a one-dimensional LynxEye detector. The monochromatization of the $\mathrm{Cu}$ radiation was ensured by a pre-sample Quartz (101) beam monochromator. Data acquisition was performed in the $2 \theta$ range between 20 and $100^{\circ}$ using a step width of $0.011^{\circ}$ and a counting time of 3 seconds. To avoid misinterpretation of the measured intensity, a fixed divergence slit (opening angle of $0.3^{\circ}$ ) was used.

\section{Results and Discussion}

The following chapter contains the catalytic, structural and spectroscopic characterization of two selected Pd-Zr systems, which are discussed in detail. The first system is an inverse model system of $\mathrm{ZrO}_{\mathrm{x}} \mathrm{H}_{\mathrm{y}}$ overlayers on Pd obtained via exposures of 500 and $1000 \mathrm{~L}$ ZTB at $723 \mathrm{~K}$. The second approach is a bulk intermetallic Pd-Zr system also discussed and characterized in detail. In previous studies, the CVD preparation of the layers and their chemical/ redox behavior were already reported $(6,15,16)$.

\section{Preparation (CVD) and Characterization of the Precatalyst State}

The main goal of the CVD prepared model catalyst was to prepare an inverse model catalyst with an intermetallic $\mathrm{Pd} / \mathrm{Zr}$ phase boundary that is easily accessible. The synthesis of metallic $\mathrm{Zr}$ was performed via CVD from a metal-organic precursor (zirconium-tertbutoxide (ZTB)). With UHV annealing treatments, the $\mathrm{ZrO}_{\mathrm{x}} \mathrm{H}_{\mathrm{y}}$-overlayers can be transformed to partially or even fully reduced $\mathrm{Zr}$. A detailed investigation of the ALD/CVD preparation technique in terms of film growth (temperature, exposure etc.) and the decomposition mechanism on $\mathrm{Pd}(111)$ can be extracted from Ref. (6)

As described in Ref. (6) annealing at $723 \mathrm{~K}$ under UHV conditions removes carbon efficiently and further UHV annealing (with the annealing time depending on the quality of the background pressure and the deposited amount of ZTB) leads to full reduction of zirconium. This can be confirmed on the basis of XP spectra. The $\mathrm{Zr} 3 \mathrm{~d}_{5 / 2}$ peak shifts from $183.15 \mathrm{eV}$ for the precursor $\left(\mathrm{Zr}^{4+}\right)$ to $179.6 \mathrm{eV}$, which is formally $\mathrm{Zr}^{0}(17,6)$. This binding energy is not representing pure metallic Zirconium but it implies a Pd-Zr alloy. The same binding energy was observed for a $\mathrm{Pt}_{3} \mathrm{Zr}$ alloy (18). Our studies clearly show that the full reduction, which is more or less surprising under these conditions because of the high oxide formation enthalpy of $-1100 \mathrm{~kJ} / \mathrm{mol}$ (19), directly correlates with the background pressure: the better the pressure, the more complete the reduction of Zirconium on Pd can be achieved. Measurements conducted in different chambers with different backgrounds lead to the conclusion that background pressures in the low $10^{-10}$ mbar range are necessary for the full reduction of $\mathrm{Zr}$ on $\mathrm{Pd}$. The following XP spectra (Figure 1) were obtained in an UHV below $10^{-10}$ mbar. 
Figure 1 shows the $\mathrm{Zr} 3 \mathrm{~d}$ region of two different experiments/exposures of $\mathrm{ZTB}$ on $\mathrm{Pd}$ (111). On the left side, an experiment with an exposure of $1000 \mathrm{~L}$ ZTB is plotted, which was deposited at $673 \mathrm{~K}$. The as-prepared state contains different components: $\mathrm{ZrO}_{\mathrm{x}} \mathrm{H}_{\mathrm{y}}(\mathrm{Zr}$

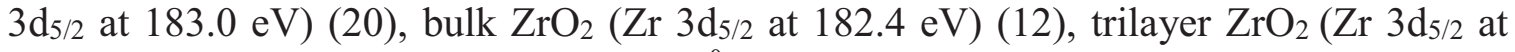
$181.0 \mathrm{eV})(17)$ and a small amount of $\mathrm{Zr}^{0}\left(\mathrm{Zr} 3 \mathrm{~d}_{5 / 2}\right.$ at $\left.179.6 \mathrm{eV}\right)(17,6,18)$. Ultra-highvacuum annealing at $723 \mathrm{~K}$ to $773 \mathrm{~K}$ leads to a loss of hydroxylated and bulk zirconium oxide and an increase of $\mathrm{Zr}^{0}$ during the first annealing cycles. The relative amount of the zirconia trilayer stays constant as long as bulk or hydroxylated zirconia are present. In the last heating cycles also the trylayer zirconia gets reduced and only $\mathrm{Zr}^{0}$ is left. The same behavior is seen for the $500 \mathrm{~L} \mathrm{ZTB}$ experiments (on the right side of Figure 1). The binding energyof the $\mathrm{Pd} 3 \mathrm{~d}_{5 / 2}$ peak stays constant at $335.4 \mathrm{eV}$, which corresponds to metallic $\mathrm{Pd}$ (11). In all corresponding C 1s spectra no carbon could be detected (not shown here).

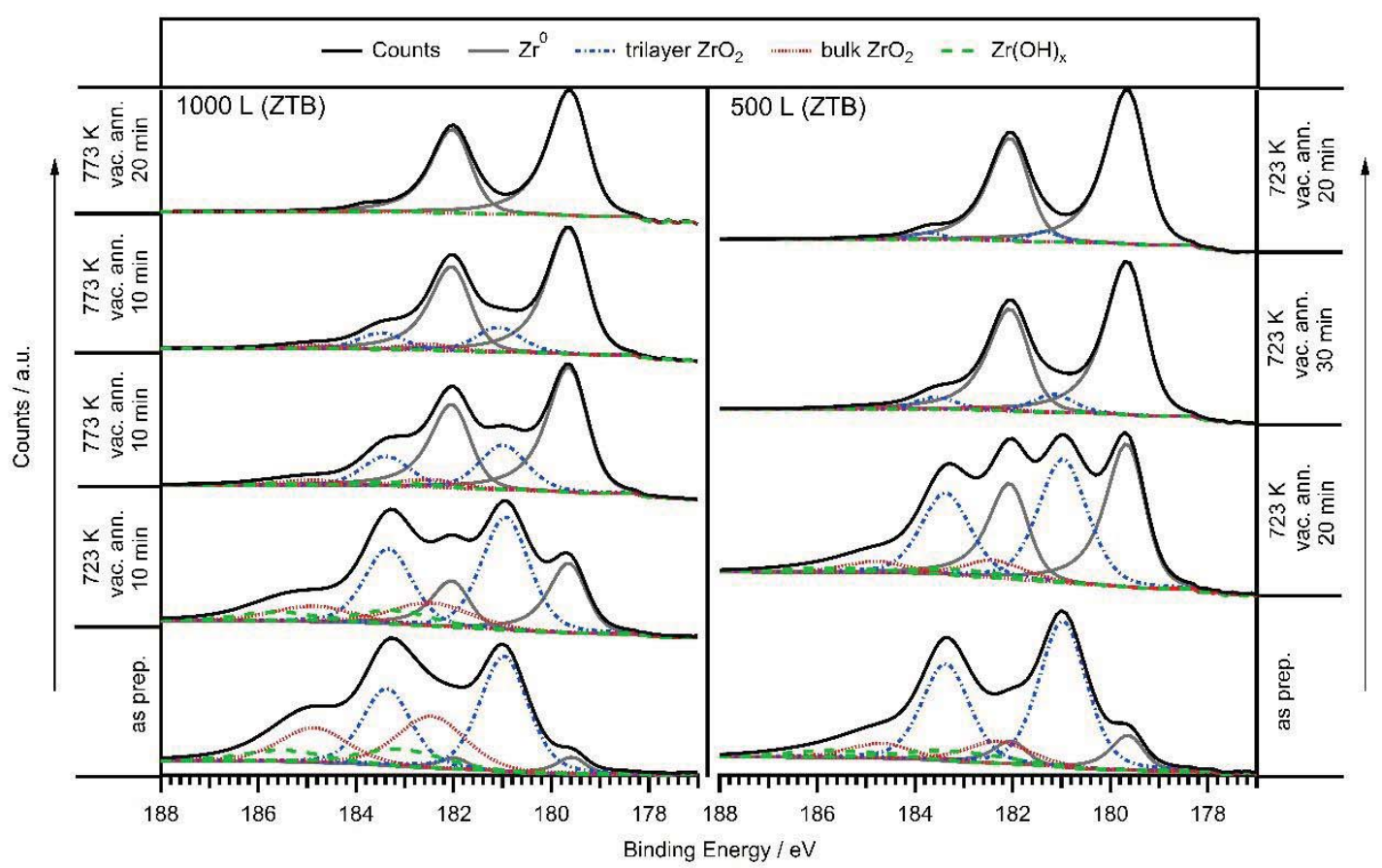

Figure 1. XP spectra (Zr 3d region) of the chemical-vapor-deposited $\mathrm{Zr}$ on a clean $\mathrm{Pd}(111)$ single crystal. Two different experiments are plotted, which are showing the reduction process: Left panel: 1000 L ZTB exposure (coverage $\sim 0.5 \mathrm{ML}$ ); Right panel: 500 L ZTB exposure (coverage $\sim 0.3 \mathrm{ML}$ ) at $723 \mathrm{~K}$ followed by different ultra-high vacuum annealing treatments. In the lowest panel, the as-prepared state is visible with different components, as described in the legend. The XP spectra after each successive annealing step are plotted (from the bottom to the top) with the applied temperature and annealing time.

With the help of STM, XPS and LEIS, the fully reduced state as well as the "intermediate reduction states" were characterized. Figure 2 shows an atomically resolved STM image of the fully reduced state. This image only shows a homogeneous near subsurface $\mathrm{Pd} / \mathrm{Zr}$ alloy. This can be determined with the help of the Fast Fourier Transform (FFT) of the STM image, which only reveals the $\operatorname{Pd}(111)$ spots. Even more important are the LEIS results. As low-energy ion scattering is sensitive to the topmost layer only, the absence of a Zr LEIS signal shows that no zirconium is sitting in the surface layer or on it. (see Figure 2c). The LEIS plot is showing three different spectra. The highest one stems from a clean $\mathrm{Pd}(111)$ single crystal, which is used as a reference for $\mathrm{Pd}$ (main peak at 662 
$\mathrm{eV}$; the small peak around $770 \mathrm{eV}$ is attributed to double scattering). The reference spectrum for $\mathrm{Zr}$ was obtained from a clean $\mathrm{Zr}(0001)$ single crystal (peak at $620 \mathrm{eV}$ ). As the spectra were obtained with neon, not helium, the peak energies are sufficiently separated, which would allow us to detect $\mathrm{Zr}$ present in the surface. Apart from somewhat different intensity (slightly different Ion currents), the peak of the Zr-modified $\mathrm{Pd}(111)$ is identical to the clean Pd reference peak (peak maxima at $662 \mathrm{eV}$ ), thus the surface layer does not contain any Zr. Nevertheless, XPS shows a distinct signal at $179.6 \mathrm{eV}$ due to the $\mathrm{Zr}^{0}$ in an alloy (18) (conforms to 0.1 ML Zr coverage), as mentioned above (Figure 2b) and no contaminations of carbon or any other impurities.

The different apparent height of the atoms in the STM image (visible as different brightness in Fig. 2a) can be explained as surface Pd atoms with or without a $\mathrm{Zr}$ neighbor below, influencing both the geometric height and the density of states, similar to the case of subsurface vanadium discussed in ref. (21).

In previous studies with smaller ZTB exposures $\left(100 \mathrm{~L}\right.$, which corresponds to a $\mathrm{Zr}^{0}$ coverage below 0.1 ML), evenly distributed sub-nanometer clusters of 1-3 atoms were detected via STM and XPS (see Ref. (6)). In fact, since this dynamic process of reductive dissolution and oxidative segregation of zirconium is completely reversible, the clusters observed there could be an intermediate oxidation state, possibly representing the nucleation for the complete trilayer oxide film. Also, the different annealing times for both experiments could have an influence ( $24 \mathrm{~min}$ for the observed clusters in ref. (6) vs. $70 \mathrm{~min}$ for the $\mathrm{Pd} / \mathrm{Zr}$ subsurface alloy shown in Figure 1 on the right side). To clearly distinguish which condition is energetically more favorable, DFT calculations are necessary and are under progress.
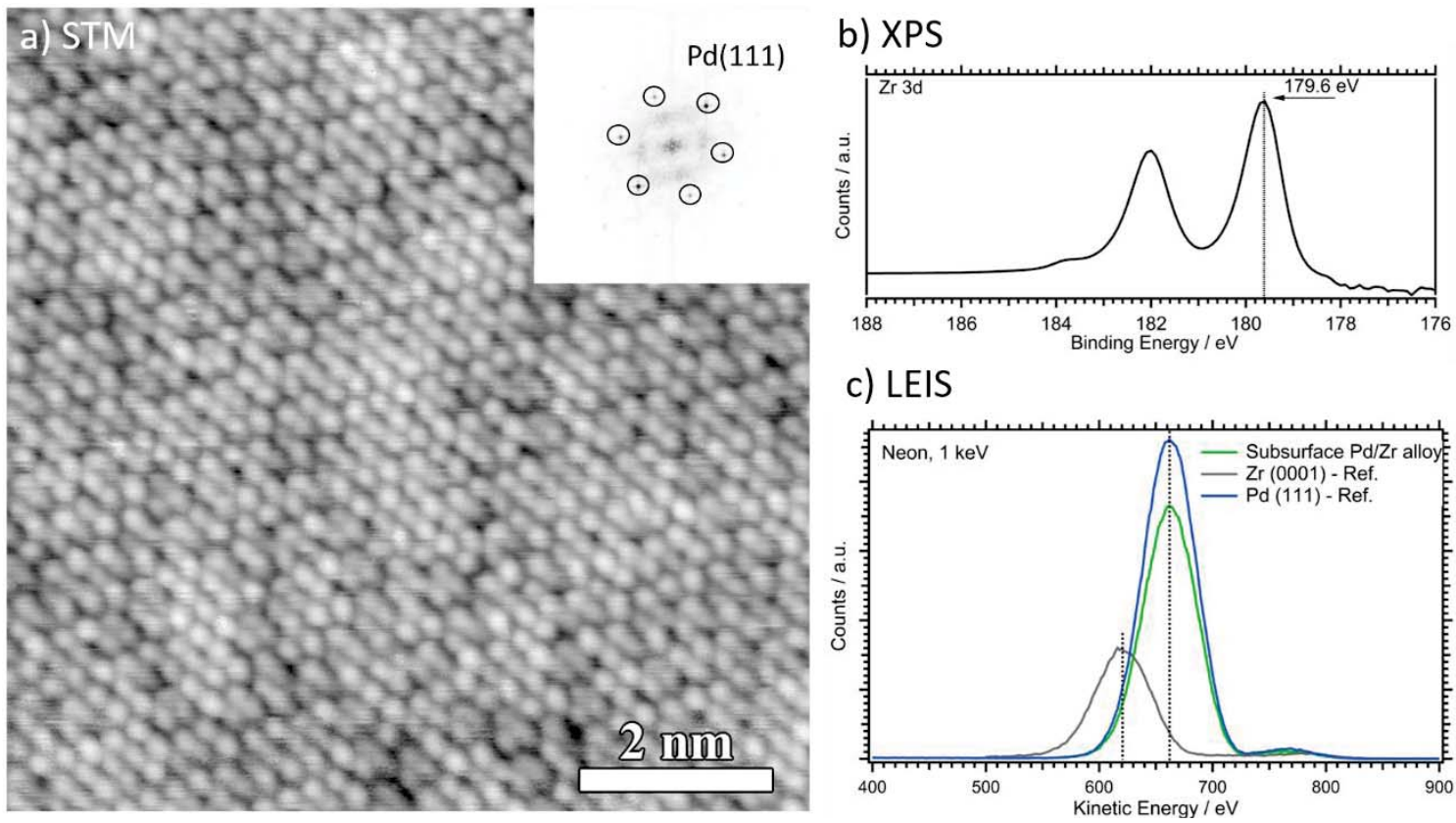

Figure 2. CVD-prepared Pd/Zr subsurface alloy (500 L ZTB exposure at $673 \mathrm{~K}$ on a clean $\mathrm{Pd}(111)$ single crystal) after annealing at $673 \mathrm{~K}$ in UHV for $70 \mathrm{~min}$. Panel a: STM image $(-2 \mathrm{mV} / 2 \mathrm{nA})$ of the fully reduced state including an inset with the FFT of this image. In the FFT, the Pd(111) spots can clearly be identified (black circles). Panel b: XP spectra of the $\mathrm{Zr} 3 \mathrm{~d}$ region. Panel c: Low-energy ion scattering (LEIS) of this surface shows only palladium. 


\section{Catalysis - Dry Reforming of Methane}

Testing of the $\mathrm{Pd} / \mathrm{Zr}^{0} / \mathrm{ZrO}_{\mathrm{x}} \mathrm{H}_{\mathrm{y}}$ model catalyst (CVD-prepared on polycrystalline $\mathrm{Pd}$ ) and the $\mathrm{Pd}: \mathrm{Zr}=2: 1$ intermetallic reference catalyst (denoted "IM") was performed in dry reforming of methane (DRM, $\mathrm{CH}_{4}+\mathrm{CO}_{2} \rightarrow 2 \mathrm{CO}+2 \mathrm{H}_{2}$ ). To promote this reaction, active sites for $\mathrm{CO}_{2}$ and $\mathrm{CH}_{4}$ activation are needed. The effect of water is not studied in this case but as referred to in refs $(6,7)$, it can in principle play a "co-catalytic" role. However, in all catalytic investigations, no water formation was detected so far.

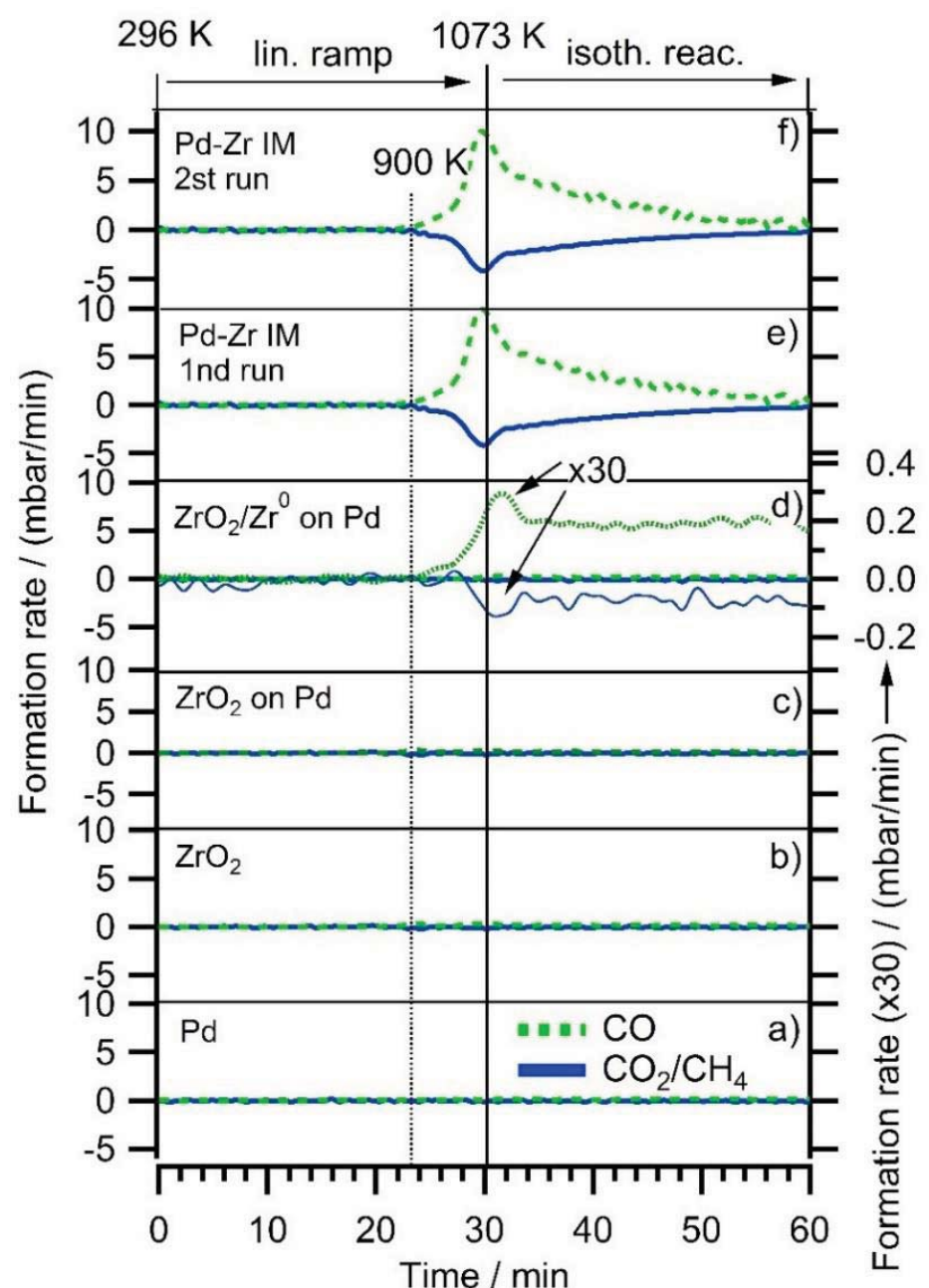

Figure 3. Reactivity pattern of the DRM reaction on a) pure, clean polycrystalline Pd foil b) clean "deep"-oxidized $\mathrm{Zr}$ foil c) $0.3 \mathrm{ML} \mathrm{ZrO}_{2}$ on Pd, prepared by post annealing of CVD grown $\mathrm{ZrO}_{\mathrm{x}} \mathrm{H}_{\mathrm{y}}$ in $5 \times 10^{-7} \mathrm{mbar}_{2}$ at $700 \mathrm{~K}$. d) $0.3 \mathrm{ML} \mathrm{Zr}^{0} / \mathrm{ZrO}_{\mathrm{x}} \mathrm{H}_{\mathrm{y}}$, prepared by annealing of $\mathrm{CVD}$ grown $\mathrm{ZrO}_{\mathrm{x}} \mathrm{H}_{\mathrm{y}}$ in $5 \times 10^{-9}$ mbar (the reactant consumption- and $\mathrm{CO}$ product formation rates were multiplied by a factor of 30 and plotted in the Y-scale range of the "IM" experiments). e-f) two subsequent DRM runs on an intermetallic $\mathrm{Pd}: \mathrm{Zr}=2: 1$ "IM" bulk phase. Initial DRM conditions: $\mathrm{CO}_{2}: \mathrm{CH}_{4}=1: 1$, total reactant pressure $100 \mathrm{mbar}$.

Figure 3 displays the results of all reactivity studies of the dry reforming reaction on different catalyst systems. To identify promotional effects and mono/-bifunctional reaction mechanisms, clean $\mathrm{Pd}$ and $\mathrm{ZrO}_{2}$ (oxidized zirconium foil) were also tested for DRM in order to complement the Pd-Zr model catalysts. After the reactions, carbon was detected by XPS on all samples, but the amount of carbon was too low to affect the overall 
stoichiometry (relative to the gaseous reactant/product amounts) and to deactivate the catalyst systems. Figure 3a) shows the selectivity/activity pattern for clean Pd which illustrates a complete inactiveness for DRM. The same behavior can be observed for pure $\mathrm{ZrO}_{2}$ (Figure 3b).

After the DRM reaction, the pure $\mathrm{ZrO}_{2}$ sample is reduced and a single state of $\mathrm{Zr}$ is detected in the XPS 3d region at a binding energy of $179.4 \mathrm{eV}$, which agrees well with literature BE values of zirconium carbide ( $\mathrm{ZrC}$ ) (22) (seen in Figure 4). Apart from carbide, $\mathrm{BE}$ of $\mathrm{C} 1 \mathrm{~s}$ at $282.0 \mathrm{eV}$, which exhibits $\mathrm{ZrC} \mathrm{(20),} \mathrm{a} \mathrm{second} \mathrm{carbon} \mathrm{component} \mathrm{is} \mathrm{observerd.}$ The second carbon component has a $\mathrm{BE}$ of $\mathrm{C} 1 \mathrm{~s}$ at $284.5 \mathrm{eV}$ and the rather large peak width (as compared to pure graphite) suggest a mix of $\mathrm{sp}^{3}$ - or $\mathrm{sp}^{2}$-hybridized carbon species.

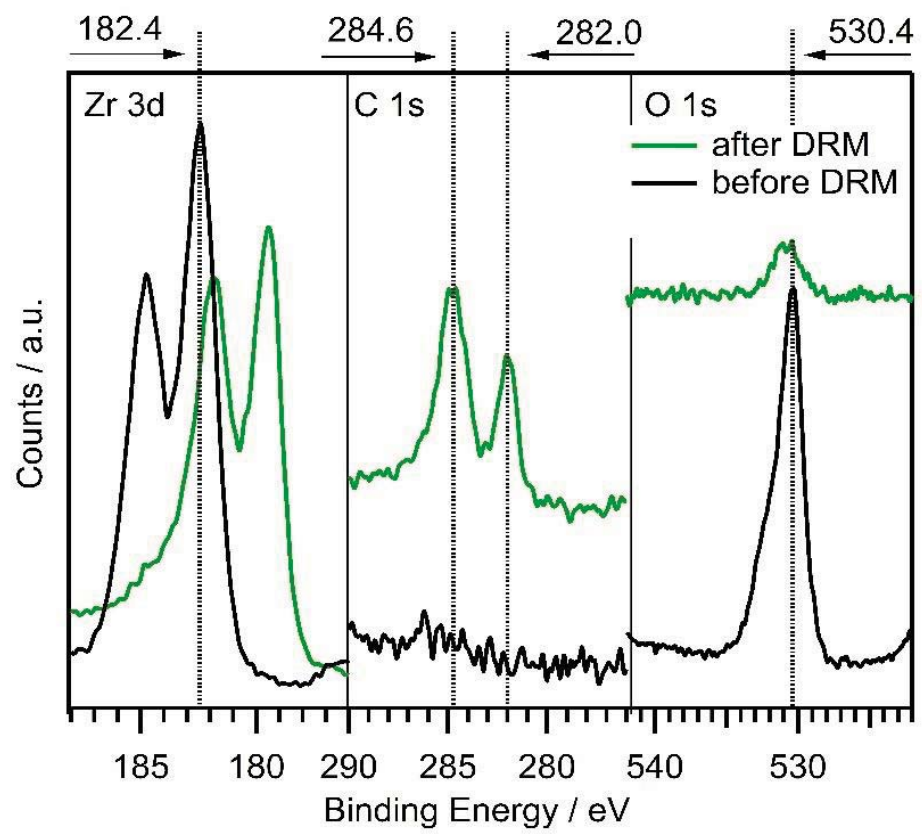

Figure 4. XP spectra of an oxidized $\mathrm{Zr}$ foil ( 1 bar $\mathrm{O}_{2}$ at $673 \mathrm{~K}$ ) before (bottom) and after (top) dry reforming of methane. The image features three different regions, namely $\mathrm{Zr} 3 \mathrm{~d}$, $\mathrm{C} 1 \mathrm{~s}$ and the $\mathrm{O} 1 \mathrm{~s}$ region. Before the reaction, no carbon and only fully oxidized zirconia $\left(\mathrm{Zr} 3 \mathrm{~d}_{5 / 2}\right.$ at $\left.182.4 \mathrm{eV}\right)$ was detected. After the reaction the $\mathrm{Zr}$ was reduced $\left(\mathrm{Zr} 3 \mathrm{~d}_{5 / 2}\right.$ at 179.4 $\mathrm{eV}$ ) and two different carbon components were detected: one species at a C 1s BE of 284.6 $\mathrm{eV}$, which is assigned to $\mathrm{sp}^{2}$ and $\mathrm{sp}^{3}$ hybridized carbon and a carbidic species $(\mathrm{ZrC})$ at $282.0 \mathrm{eV}(22,11)$.

A CVD-prepared and oxygen-annealed $\left(5 \times 10^{-7} \mathrm{mbar}\right) \mathrm{Pd} / \mathrm{ZrO}_{2}$ inverse model catalyst was also tested for dry reforming of methane, as highlighted in Figure 3c). There, no conversion/activity in the DRM reaction can be observed. From XPS it is known that this sample only consists of pure $\mathrm{ZrO}_{2}$ and no metallic $\mathrm{Zr}$ (see Figure 5a). After the DRM reaction, no changes except for the formation of carbon were observed. In clear contrast to these results, the presence of a small amount of $\mathrm{Zr}^{0}$ leads to a detectable formation rate of CO.

Figure 3d) shows data for a CVD-prepared and afterwards UHV-annealed $\mathrm{Zr}^{0} / \mathrm{ZrO}_{\mathrm{x}} \mathrm{H}_{\mathrm{y}}$ overlayer on a polycrystalline $\mathrm{Pd}$ foil. In this case, the reactivity/activity pattern exhibits a selective conversion of $\mathrm{CH}_{4}$ and $\mathrm{CO}_{2}$ to $\mathrm{CO}$ and $\mathrm{H}_{2}$, although the formation rate is rather low. In the corresponding XP spectra (before and after the reaction, seen in Figure $5 \mathrm{~b}$ ), the $\mathrm{Zr} 3 \mathrm{~d}$ region displays a small $\mathrm{Zr}^{0}$ component $(\mathrm{BE} \sim 179.6 \mathrm{eV})$, indicated by an arrow, next to zirconia $\left(\mathrm{Zr} 3 \mathrm{~d}_{5 / 2}\right.$ at $\left.182.4 \mathrm{eV}\right)$ and hydroxylated $\mathrm{Zr}\left(\mathrm{Zr} \mathrm{3d_{5/2 }}\right.$ at $\left.183.0 \mathrm{eV}\right)$. 
To prove the identified active sites for DRM, a real catalyst sample, prepared via intermetallic co-melting of the pure components, was tested. The intermetallic sample have a nominal ratio of $\mathrm{Pd} / \mathrm{Zr}=2 / 1$ and the identified phases before and after the reaction are shown in Figure 6. After preparation, the intermetallic sample consist of $\mathrm{Pd}_{2} \mathrm{Zr}$ and a minor component of $\mathrm{Pd}_{3} \mathrm{Zr}$ (which is the thermodynamically most stable phase in the $\mathrm{Pd} / \mathrm{Zr}$ phase diagram) and metallic Pd bulk phases. XPS (Figure 5c) indicates that the "IM" sample also consist of different components and again the $\mathrm{Zr}^{0}$ component is indicated by an arrow. The catalytic testing of these samples (shown in Figure 3, section e and f) revealed an highly active catalyst. A subsequently performed second catalysis cycle shows exactly the same catalytic behavior, although carbon was already deposited on the surface due to methane decomposition during the first cycle. This is also the reason why no other signals except carbon can be detected by XPS after the reaction (Figure 5c). The high amount of carbon deposition does not appear on pure Pd (not shown here). The deposited carbon species can be associated to a mix of $\mathrm{sp}^{3}$ - or $\mathrm{sp}^{2}$-hybridized carbon species as derived from the binding energy of $\mathrm{C} 1 \mathrm{~s}$ region at $284.5 \mathrm{eV}$ and the rather large peak width (as compared to pure graphite).

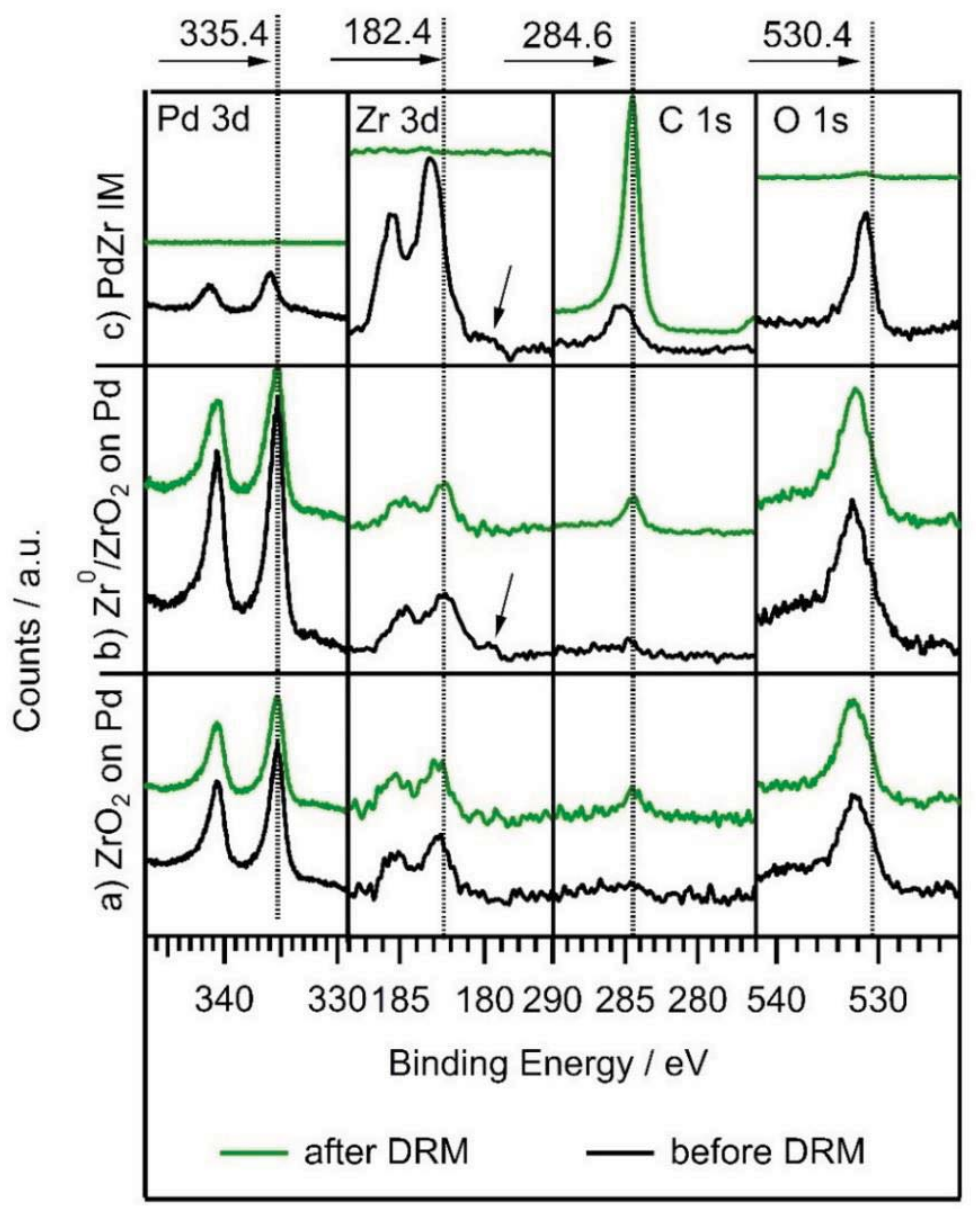

Figure 5. XP spectra ( $\mathrm{Pd} \mathrm{3d}, \mathrm{Zr} 3 \mathrm{~d}, \mathrm{C} 1 \mathrm{~s}$ and $\mathrm{O} 1 \mathrm{~s}$, which overlaps with the $\mathrm{Pd} 3 \mathrm{p}$ region) before (black) and after (green) the DRM experiments for: a) $0.3 \mathrm{ML} \mathrm{ZrO}_{2}$ on polycrystalline $\mathrm{Pd}$, prepared by annealing of CVD-prepared $\mathrm{Zr}^{0} / \mathrm{ZrO}_{\mathrm{x}} \mathrm{H}_{\mathrm{y}}$ in $5 \times 10^{-7} \mathrm{mbar}$ $\mathrm{O}_{2}$ at $700 \mathrm{~K}$ for 10 minutes; b) $0.3 \mathrm{ML} \mathrm{Zr}^{0} / \mathrm{ZrO}_{\mathrm{x}} \mathrm{H}_{\mathrm{y}}$ on polycrystalline Pd foil prepared by annealing of a CVD-grown $\mathrm{ZrO}_{\mathrm{x}} \mathrm{H}_{\mathrm{y}}$ in vacuum $\left(5 \times 10^{-9} \mathrm{mbar}\right)$ at $700 \mathrm{~K}$; c) the intermetallic $\mathrm{Pd} / \mathrm{Zr}(2: 1)$ "IM" bulk phase before the first and after the second DRM run. The $\mathrm{Zr}^{0}$ component is indicated by arrows. 
$\underline{\text { X-ray Diffraction - Pd-Zr Intermetallic Bulk Phases: }}$

The characterization of the intermetallic, co-melted $\mathrm{Pd}-\mathrm{Zr}$ phases has been carried out with XRD and XPS (see previous chapter). Figure 6 compares the XRD-derived bulk structures before and after the dry reforming of methane experiment up to $1073 \mathrm{~K}$. Before the catalysis testing (DRM), X-ray diffraction indicates the presence of a body-centered tetragonal $\mathrm{Pd}_{2} \mathrm{Zr}$ phase $(7,24)$ in co-existence with metallic $\mathrm{Pd}(\mathrm{fcc})$. Also, a minor component of $\mathrm{Pd}_{3} \mathrm{Zr}(7,25)$ can be observed. The original lattice parameters of the $\mathrm{Pd}_{2} \mathrm{Zr}$ structure (labeled: $\mathrm{Pd}_{2} \mathrm{Zr}$ (tetragonal body centered) b)) in Figure 6), have been compressed slightly (labeled: $\mathrm{Pd}_{2} \mathrm{Zr}$ (tetragonal body centered) b in Figure 6) to fit the XRD pattern. For fitting the XRD pattern, it was necessary to assume $\mathrm{Pd}_{2} \mathrm{Zr}$ lattice parameters of $a=$ $3.3631 \mathrm{pm}, c=8.4178 \mathrm{pm}$ (green ticks in Fig. 6a), about 1\% smaller than the values from the literature (ref. (24); brown ticks in Fig. 6a). A possible reason for the deviation in the lattice parameters could be a differing $\mathrm{Zr}$ concentration as compared to the reference. After the dry reforming of methane, XRD reveals many changes. Obviously, a transformation of the $\mathrm{Pd}_{2} \mathrm{Zr}$ phase to $\mathrm{Pd}(\mathrm{fcc})$ and $\mathrm{Pd}_{3.6} \mathrm{Zr}$ (26) phases takes place. The $\mathrm{Pd}_{3} \mathrm{Zr}$ phase seems to be rather stable. The remaining $\mathrm{Zr}$ crystallizes in monoclinic as well as tetragonal $\mathrm{ZrO}_{2}(27$, 28). Also, there appear to be signals originating from $\alpha-\operatorname{Zr}(29)$. However, further studies (e.g. by transmission electron microscopy) are required to confirm the existence of this metallic phase.

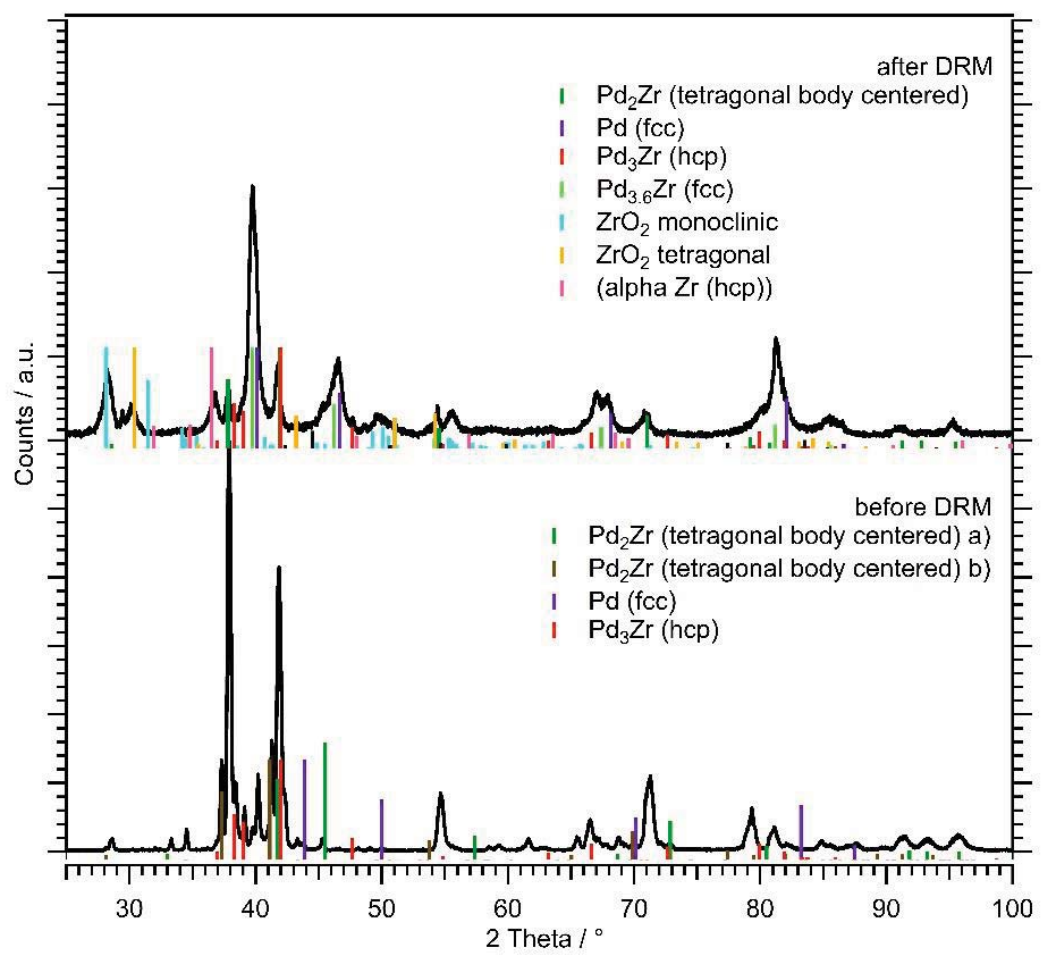

Figure 6. X-ray diffraction patterns (measured in reflection) of $\mathrm{Pd} / \mathrm{Zr}(\mathrm{Pd}: \mathrm{Zr}=2: 1)$ before and after DRM. Before the reaction, XRD reveals three components/phases: $\mathrm{Pd}_{2} \mathrm{Zr}, \mathrm{Pd}_{3} \mathrm{Zr}$ and metallic $\mathrm{Pd}$. After the reaction it is getting more complex and new components namely $\mathrm{Pd}_{3.6} \mathrm{Zr}$, monoclinc and tetragonal $\mathrm{ZrO}_{2}, \alpha-\mathrm{Zr}$ and carbon species can be observered. The intensity of the Pd peaks has increased and Pd-rich phases as well as $\mathrm{ZrO}_{2}$ and $\mathrm{Zr}$ phases were formed. The amount of $\mathrm{Pd}_{2} \mathrm{Zr}$ decreases accordingly. 


\section{Conclusion}

An active $\mathrm{Pd}-\mathrm{Zr}$ dry reforming catalyst with high activity is only achieved if the $\mathrm{Zr}^{0}$ species either in a CVD prepared (reduced via annealing in vacuum) or bulk intermetallic $\mathrm{Pd}-\mathrm{Zr}$ "pre-catalyst" (produced via co-melting) are initially present. Single crystal studies revealed that after full reduction the surface only consists of pure palladium and zirconium is located in subsurface regions. Under reaction conditions zirconium segregates back to the surface and the surface consists of $\mathrm{Zr}^{4+} \mathrm{O}_{\mathrm{x}} \mathrm{H}_{\mathrm{y}}$ components which are produced in situ via reactive hydroxylation/oxidation during the reaction. This cannot be deduced for the bulk intermetallic sample because of the high amount of carbon deposition. The performance of the intermetallic "melt" pre-catalyst with a nominal $\mathrm{Pd}^{0} / \mathrm{Zr}^{0}$ ratio of $2 / 1$ can be summarized as exhibiting the highest observed formation rates. It is conceivable that this process is responsible for creating a high amount of active sites and/or an active phase boundary. No carbidic products were observed so far on the investigated CVD- and intermetallic melt-prepared catalyst. For clear and detailed information about the $\mathrm{CO}_{2}$ activation process, further DFT calculations and in situ catalysis/spectroscopy experiments will be performed. Another major insight is the beneficial carbon chemistry and the reactive carbon behaviour, respectively. Carbon deposition is visible on the surface but does not appear to deactivate the catalyst.

\section{Acknowledgments}

The work was performed within the platform "Material- and Nanoscience" at the University of Innsbruck and the Institute of Applied Physics at the Vienna University of Technology. Financial support of the SFB project FOXSI F4503, F4505 and F4501, funded by the Austrian Science Fund and the doctoral program "Reactivity and Catalysis" funded by the University of Innsbruck is greatly acknowledged.

\section{References}

1. L. Barelli and A. Ottaviano, Energy, 71, 118-129 (2014).

2. R. Suwanwarangkul, E. Croiset, E. Entchev, S. Charojrochkul, M. D. Pritzker, M. W. Fowler, P. L. Douglas, S. Chewathanakup and H. Mahaudom, J. Power Sources, 161(1), 308-322 (2006).

3. L. Mayr, R. Rameshan, B. Klötzer, S. Penner and C. Rameshan, Rev. Sci. Instrum., 85(5), 55104 (2014).

4. J. I. J. Choi, W. Mayr-Schmolzer, F. Mittendorfer, J. Redinger, U. Diebold and M. Schmid, J. Phys.: Condens. Matter, 26(22), 225003 (2014).

5. D. C. Bradley and J. D. Swanwick, J. Chem. Soc., 748 (1959).

6. L. Mayr, X.-R. Shi, N. Kopfle, C. A. Milligan, D. Y. Zemlyanov, A. KnopGericke, M. Havecker, B. Klotzer and S. Penner, Phys. Chem. Chem. Phys., 18(46), 31586-31599 (2016).

7. N. Köpfle, L. Mayr, D. Schmidmair, J. Bernardi, A. Knop - Gericke, M. Hävecker, B. Klötzer and S. Penner, Catalysts, 7(2), 53 (2017).

8. A. Gharachorlou, M. D. Detwiler, X.-K. Gu, L. Mayr, B. Klotzer, J. Greeley, R. G. Reifenberger, W. N. Delgass, F. H. Ribeiro and D. Y. Zemlyanov, ACS Appl. Mater. Interfaces, 7(30), 16428-16439 (2015). 
9. A. Gharachorlou, M. D. Detwiler, L. Mayr, X.-K. Gu, J. Greeley, R. G. Reifenberger, W. N. Delgass, F. H. Ribeiro and D. Y. Zemlyanov, J. Phys. Chem. C, 119(33), 19059-19072 (2015).

10. CasaXPS, Casa Software Ltd (2011).

11. J. F. Moulder, W. F. Stickle, P. E. Sobol, K. D. Bomben, J. Chastain and R. C. King Jr., Editors, Handbook of X-ray photoelectron spectroscopy: A reference book of standard spectra for identification and interpretation of XPS data, Eden Prairie, Minn., Physical Electronics (1995).

12. D. Majumdar and D. Chatterjee, J. Appl. Phys., 70(2), 988 (1991).

13. Powell C. J. , Jablonski A., NIST Electron Effective-Attenuation-Length Database SRD 82(Version 1.3) (2011).

14. J. J. Yeh and I. Lindau, At. Data Nucl. Data Tables, 32(1), 1-155 (1985).

15. M. Valden, Science, 281(5383), 1647-1650 (1998).

16. L. Mayr, X. Shi, N. Köpfle, B. Klötzer, D. Y. Zemlyanov and S. Penner, Journal of Catalysis, 339, 111-122 (2016).

17. S. Sinha, S. Badrinarayanan and A. Sinha, J. Less-Common Met., 134(2), 229236 (1987).

18. H. Li, J.-I. J. Choi, W. Mayr-Schmölzer, C. Weilach, C. Rameshan, F. Mittendorfer, J. Redinger, M. Schmid and G. Rupprechter, J. Phys. Chem. C, 150127093244008 (2015).

19. M. W. Chase, J. Phys. Chem. Ref. Data, Monogr., 1-1951 (1998).

20. C. Huang, Z. Tang and Z. Zhang, J. Am. Ceram. Soc., 84(7), 1637-1638 (2001).

21. C. Konvicka, Y. Jeanvoine, E. Lundgren, G. Kresse, M. Schmid, J. Hafner and P. Varga, Surf. Sci., 463(3), 199-210 (2000).

22. R. Kaufmann, H. Klewe-Nebenius, H. Moers, G. Pfennig, H. Jenett and H. J. Ache, Surf. Interface Anal., 11(10), 502-509 (1988).

23. K. H. Lim, Z.-X. Chen, K. M. Neyman and N. Rosch, J. Phys. Chem. B, 110(30), 14890-14897 (2006).

24. K. Schubert, S. Bhan, W. Burkhardt, R. Gohle, H. G. Meissner, M. Pötzschke and E. Stolz, Naturwissenschaften, 47(13), 303 (1960).

25. O. V. Yazyev and S. G. Louie, Nat. Mater., 9(10), 806-809 (2010).

26. K. Baba, U. Miyagawa, K. Watanabe, Y. Sakamoto and T. B. Flanagan, J. Mater. Sci., 25(9), 3910-3916 (1990).

27. P. Bouvier, E. Djurado, C. Ritter, A. Dianoux and G. Lucazeau, Int. J. Inorg. Mater., 3(7), 647-654 (2001).

28. Mc Murris, H. Morris, M., Evans, E., Paretzkin, B.,Wong-Ng, W., Hubbard, C., Powder Diffr.(01), 275 (1986).

29. B. D. Lichter, Trans. Metall. Soc. AIME(218), 1015-1018 (1960). 